\title{
A New Conductive Ink for Microstrip Antenna and Bioinspired FSS Designs on Glass and Fiberglass Substrates
}

\author{
Marcelo David S. Mesquita ${ }^{1,2} \mathbb{E}$, Adaildo Gomes D’Assunção ${ }^{1} \mathbb{D}$, João Bosco L. Oliveira ${ }^{1} \mathbb{D}$, \\ Yuri Max Vieira Batista ${ }^{1}$ (D) \\ ${ }^{1}$ Federal University of Rio Grande do Norte, UFRN, Caixa Postal 1655, CEP: 59078-970, Natal, RN, Brazil \\ ${ }^{2}$ Instituto Federal de Educação, Ciência e Tecnologia do Rio Grande do Norte, IFRN, CEP: 59290-000, São \\ Gonçalo do Amarante, RN, Brazil \\ marcelo.prof.fis@gmail.com, adaildo@ct.ufrn.br, boscolucena@gmail.com,yurimax@live.com
}

\begin{abstract}
This paper describes an investigation of the possibility of using a new conductive ink, instead of copper clad laminates, in the manufacturing of microstrip patch antennas on glass and fiberglass substrates and of bioinspired frequency selective surfaces (FSSs) on fiberglass substrates for wireless communication systems. The new conductive ink is developed using synthesized nitrocellulose which, in ethyl acetate solution, works as a bonding agent and carrier for the formation of a conductive film. The load used in the fabrication process is silver metallic powder. Simulation and analysis are performed using Ansoft Designer and HFSS softwares. Microstrip antenna and FSS prototypes are fabricated and measured for comparison purpose. An agreement is observed between simulation and measurements results.
\end{abstract}

Index Terms - Conductive ink, FSS, microstrip antenna, nitrocellulose, silver ink.

\section{INTRODUCTION}

The development of circuit technology for wireless communication systems is requiring the design of planar, compact, flexible, and reconfigurable structures. This demand applies to the development of new antennas, frequency selective surfaces (FSSs), materials, and fabrication techniques [1]. In order to meet these requirements, planar antenna and FSS structures need to be more versatile in their shapes and applications [1].

In the last decade, several works have been carried out with the use of conductive ink printing technology [2]-[5], aiming to reduce waste and cost of tools to accelerate the production process and to enable the realization of complex designs. This flexibility allows the fabrication of complex components and significantly reduces the manufacturing process of RF circuits for wireless communication systems.

Ref. [2] proposes the use of inkjet printing of ultra-wideband (UWB) antennas on low-cost acrylonitrile butadiene-styrene/polycarbonate (ABS/PC) thermoplastic substrates which present good mechanical and thermal properties. The ink used is $40 \%$ by weight of silver nanoparticles from Sun Chemicals (Ref 5714). Simulation and measurement results are in good agreement.

A low cost and an environmentally friendly inkjet printing technique on a paper substrate is presented Brazilian Microwave and Optoelectronics Society-SBMO received 24 Nov 2018; for review 29 Nov 2018; accepted 11 Apr 2019 
in [3] for the fabrication of an antenna that can be used as a sensor in a wide range of applications in biomedical devices. The antenna is manufactured using ANP silver jet 55LT-25C ink. The substrate is a common photographic paper from Kodak.

Microstrip antennas were fabricated in [4] using a new technique of inkjet printing on textile substrates. The antennas' substrate is a mixed fabric composed of polyester and cotton. The conductive ink for printing was U5714 from Sun Chemical which is commercially available.

In [5], a multi-layer microstrip patch antenna is printed with the ANP silver jet DGP-40LT-15C ink (ANP Corporation, Sejong-si, South Korea) which contains 30-35\% silver nanoparticles dispersed in a TGME (triethylene glycol monoethyl ether) with the ink-jet printing technique, again demonstrating that conductive inks can be applied in the antennas manufacture.

In this work, it is investigated the possibility of using commercially available carbon ink and an ink synthesized from nitrocellulose without additives and with silver metallic powder, for the design and fabrication of prototypes of microstrip antennas and FSSs as an alternative to conventional printed circuit techniques, such as the use of prototyping, heat transfer, and perchloride of iron corrosion of printed circuit boards. In addition, this technique simplifies the fabrication of printed circuits, being efficient, accurate, low cost and versatile. Furthermore, this technique can be used in the fabrication of antennas, FSSs, and filters with bioinspired, fractals and metamaterials patch geometries of planar and non-planar structures.

Therefore, this work aims at proposing, manufacturing and characterizing a new conductive silver ink, from nitrocellulose, to be used in the development of planar circuits for applications in wireless communication systems. Initially, the fabricated conductive ink is used in the development of microstrip patch antennas, similarly to works carried out in [2]-[5]. In addition, the fabricated conductive ink is used in the development of bioinspired frequency selective surfaces, which are more complex structures, such as those of rectangular periodic arrays of conducting patches elements with the leaf shape of triangularis plant of the genus Oxalis.

Microstrip antennas and FSS simulations and analyses are performed using Ansoft Designer and HFSS softwares. For comparison purpose, microstrip antenna and FSS prototypes are fabricated with the painting method by simple brushing and spraying. Afterward, the antennas prototypes were measured for comparison purpose. Good agreement is observed between simulation and measurements results, for both microstrip antennas and FSS structures.

Section 2 introduces the synthesis of a new conductive ink which is suitable for painted microwave circuit fabrication and exhibits a better electrical conductivity than a commercially available.

Section 3 presents the simulated and measured results for the developed antennas painted with the fabricated conductive ink. Similarly, Section 4 presents the simulated and measured results for the bioinspired FSS structure. The simulated and measured results obtained for the considered microstrip antenna and FSS structures are discussed in Section 5. Section 6, presents the main conclusions of this work. 


\section{THE CONDUCTIVE INK PREPARATION}

Nitrocellulose is used to produce resins entering the basic composition of inks and varnishes. They are produced by the reaction of cellulose with nitric acid in the presence of sulfuric acid [6].

To obtain nitrocellulose, a sulfonitrile solution was initially prepared. It was expected to stabilize, to add cellulose in small portions, leaving to act for 30 minutes. After this time, the cellulose is washed in order to neutralize the remaining acid. After drying the cellulose, the result is a cotton with a rougher consistency, which has very high flammability.

To dissolve the nitrocellulose, ethyl acetate was used, obtaining a colloidal solution, afterwards being passed through the simple filtration process, only to be added the metallic powdered silver (with control of granulometry up to $35 \mu \mathrm{m}$ ) under moderate agitation.

As a way of obtaining a morphology and identification of the chemical elements of the conducting surface, scanning electron microscopy (SEM) and dispersive energy spectroscopy (EDS) techniques [7] are used to get their respective spectra images, as shown in Figs. 1 and 2, respectively. The EDS results for the element weight percent and atomic percent are shown in Table I.

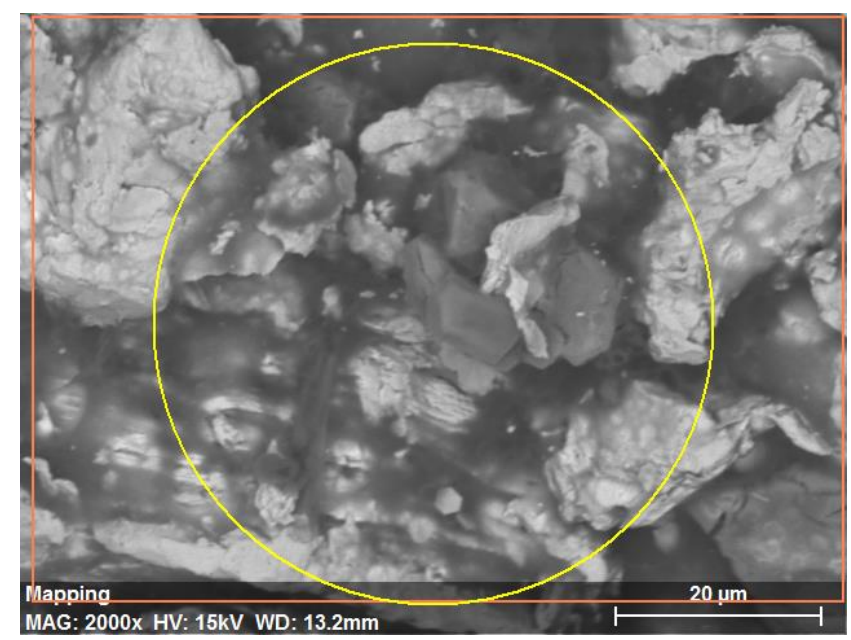

Fig. 1. SEM image showing the arrangement of the particles on the fiberglass substrate [8].

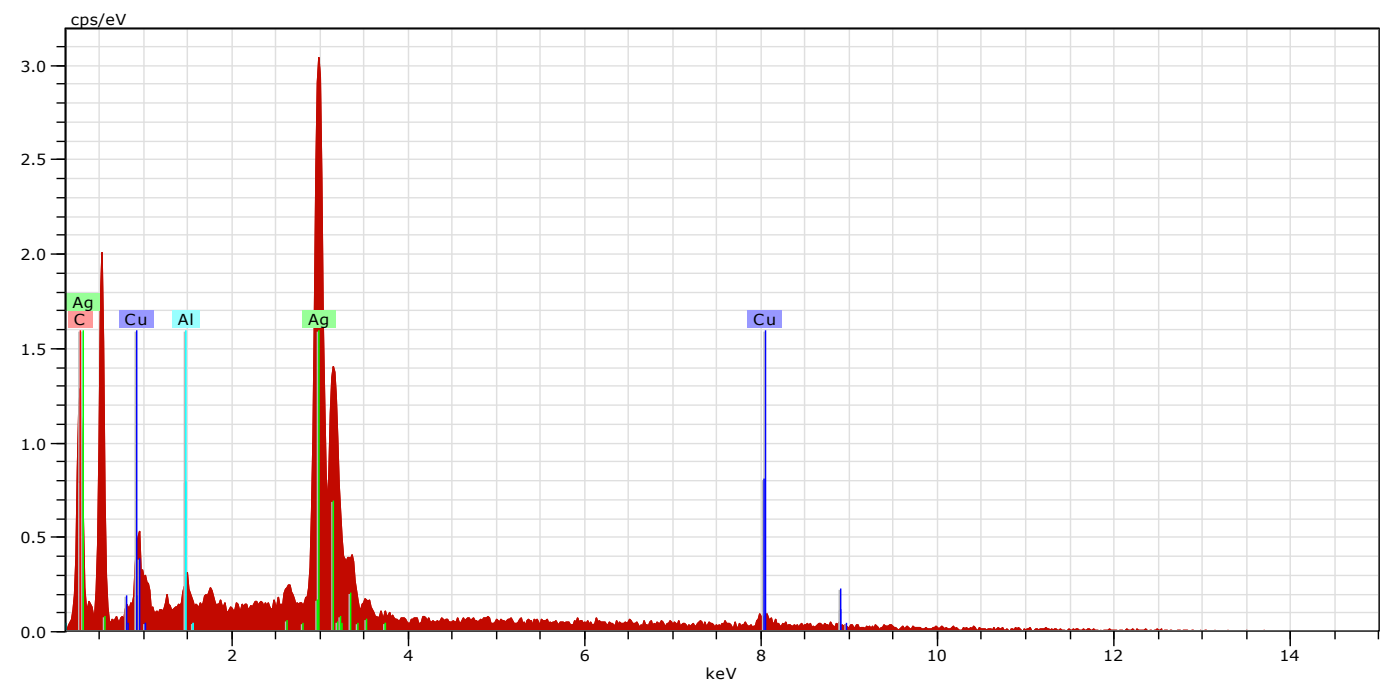

Fig. 2. The spectrum obtained by microanalysis of characteristic X-rays by EDS. 

DOI: http://dx.doi.org/10.1590/2179-10742019v18i21554

\begin{tabular}{|c|c|c|}
\hline Element & [weight \%] & [atomic \%] \\
\hline Carbon & 13.94 & 56.62 \\
\hline Silver & 78.31 & 35.42 \\
\hline Copper & 5.81 & 4.46 \\
\hline Aluminum & 1.94 & 3.50 \\
\hline
\end{tabular}

The weight percentage of atoms supplied by the scanning electron microscope for the same sample shown in Fig. 1 was $13.94 \%$ for carbon, $78.31 \%$ for silver, 5.81\% for copper and 1.94\% for aluminum. Fig. 3 shows an image for carbon, copper and silver components present in the considered sample.

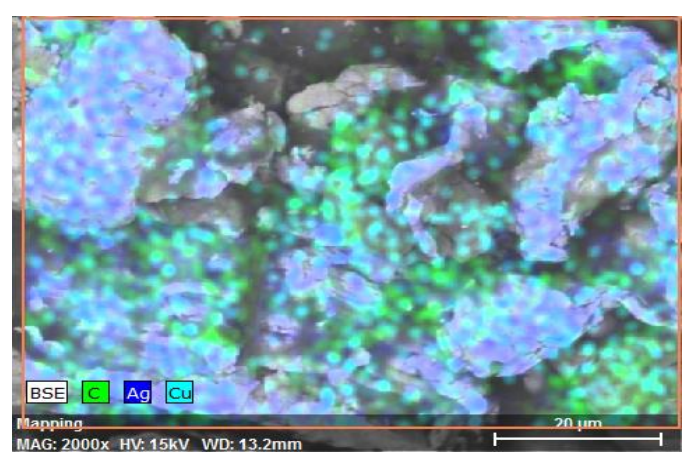

Fig. 3. EDS image formed for the study.

Fig. 4 presents the steps performed to obtain the nitrocellulose, as well as the process of synthesis of the conductive ink.

The incorporation of electrically conductive particles into a polymeric insulating matrix, such as the nitrocellulose discussed herein, is an important example of the materials modification in hitherto restricted areas to metals, such as conductive adhesives found commercially. This class is called polymer composite conductors which have many advantages compared to metals [8], namely, processability and cost, and a new process without the need of perchloride of iron corrosion, conventionally made.

When a certain concentration of conductive charge is added to a polymer matrix, it is observed that the matrix that previously presented nonconductive behavior starts to conduct electric current. In general, a conductive composite has two phases, a conductive and a nonconductive. Such systems present a percolation threshold that is studied by [9], which explain the conditioning mechanism in this conductive composite. 


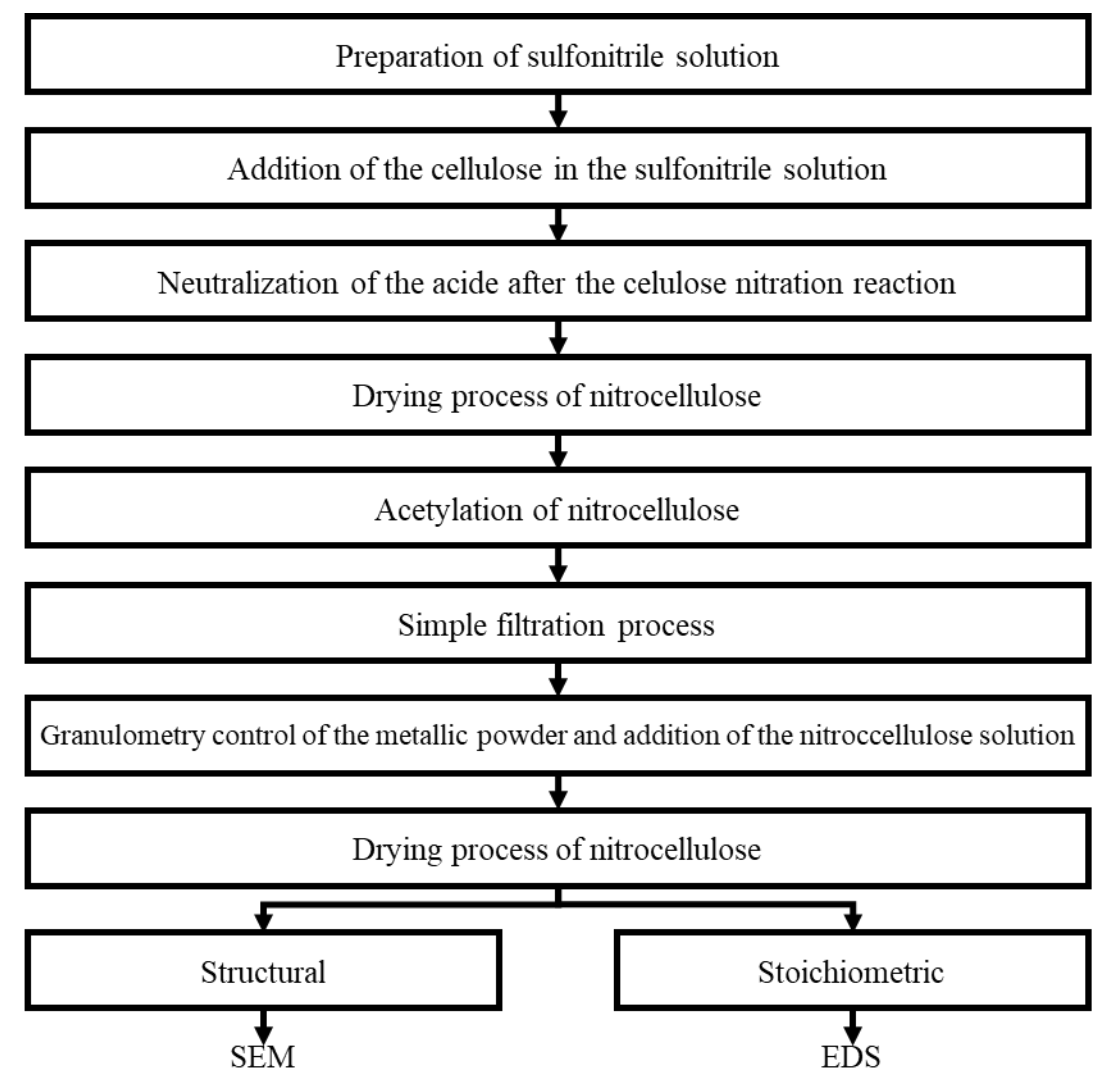

Fig. 4. Block diagram of the conductive ink synthesis process.

The percolation theory is used because it allows an interpretation of the electric conductivity behavior. According to this theory, the electrical conductivity of a composite is directly dependent on the concentration of conductive material added to the insulating matrix [10].

Thus, a low concentration of conductive material causes isolated clumps. However, as the concentration of this material increases, it generates large clumps, thus allowing the appearance of a conductive path. The results presented in Table I indicate a concentration of $78.31 \%$ of silver atoms in the analyzed surface which is more than enough to guarantee the electrical percolation. In addition, as the silver concentration in the conductive film is high, larger clusters occur, allowing the formation of a conductive path.

The proposed, manufactured and characterized new conductive silver ink from nitrocellulose is used in the fabrication of microwave integrated circuits (antennas and FSSs) to investigate the possibility of its use as an alternative to copper clad laminates. Two planar structures are fabricated for testing and characterization. The first one is a $2.45 \mathrm{GHz}$ small size typical rectangular microstrip antenna. The second one is a large size innovative $3.5 \mathrm{GHz}$ bioinspired frequency selective surface (FSS). The microstrip antenna and bioinspired FSS structures, designs and results are presented in the following sections. 


\section{ReCtANGULAR Microstrip ANTENNA DESIGN, FABRICATION AND RESUlts}

Typically, a rectangular microstrip antenna is composed of a conducting patch of width $\mathrm{W}$ and length $\mathrm{L}$, printed on a dielectric substrate, of height $\mathrm{h}$, relative permittivity $\varepsilon_{\mathrm{r}}$, and loss tangent $\tan \delta$, which is mounted on a ground plane as illustrated in Fig. 5.

In this work, the inset-feed technique is used to improve the impedance matching between the microstrip line and the antenna input impedance. The inset-feed physical dimensions are length $\mathrm{y}_{0}$, slot width $\mathrm{x}_{0}$, and strip width $\mathrm{W}_{0}$, which is the same of the feeding microstrip line, as shown in Fig. 5 . The overall feeding length of the microstrip line is $\mathrm{L}_{0}$.

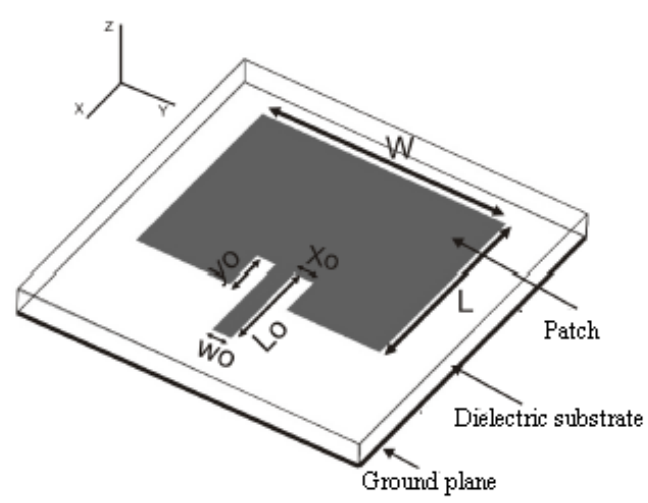

(a)

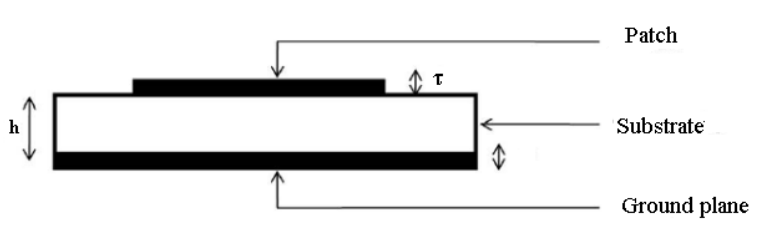

(b)

Fig. 5. The geometry of a rectangular microstrip patch antenna. (a) 3D illustration and (b) cross-sectional view.

The analysis of the rectangular microstrip antenna is performed using the approximate expressions given in (1) to (4) [1], [11].

$$
\begin{gathered}
W=\frac{c}{2 f_{r}} \sqrt{\frac{2}{\varepsilon_{r}+1}} \\
\varepsilon_{r e f f}=\frac{\varepsilon_{r}+1}{2}+\frac{\varepsilon_{r}-1}{2}\left[1+12 \frac{h}{W}\right]^{-1 / 2} \\
\frac{\Delta L}{h}=0.412 \frac{\left(\varepsilon_{r e f f}+0.300\right)\left(\frac{W}{h}+0.264\right)}{\left(\varepsilon_{r e f f}+0.258\right)\left(\frac{W}{h}+0.813\right)} \\
L=\frac{c}{2 f_{r} \sqrt{\varepsilon_{r}}}-2 \Delta L
\end{gathered}
$$

where $c$ is the light velocity in free space, $\varepsilon_{r}$ is the relative permittivity of the substrate material, $f_{r}$ is the resonant frequency, $h$ is the dielectric substrate height, $\varepsilon_{\text {reff }}$ is the effective permittivity, and $\Delta \mathrm{L}$ is the fringing length [12].

In addition, the inset-feed width, $\mathrm{x}_{0}$, and length, $\mathrm{y}_{0}$, are determined to provide the antenna input 
impedance matching. The initial value of $\mathrm{x}_{0}$ is $1 \mathrm{~mm}$ and the value of $\mathrm{y}_{0}$ is calculated using the approximate expression in (5) [1], [11].

$$
y_{0}=\frac{L}{\pi} \operatorname{acos}\left(\sqrt{\frac{50}{R_{\text {in }}(0)}}\right)
$$

Where the antenna input resistance, $\mathrm{R}_{\text {in }}(0)$, is given by,

with

$$
R_{i n}(0)=\frac{1}{2\left(G_{1} \pm G_{12}\right)}
$$

$$
G_{l}=\frac{W}{120 \lambda_{0}}\left[1-\frac{1}{24}\left(k_{0} h\right)^{2}\right]
$$

and

$$
G_{12}=\frac{W}{120 \pi^{2}} \int_{0}^{\pi}\left[\frac{\sin \left(\frac{k_{0} \mathrm{w}}{2} \cos \theta\right)}{\cos \theta}\right]^{2} j_{0}\left(k_{0} L \sin \theta\right) \sin ^{3} \theta d \theta
$$

where $\mathrm{k}_{0}$ and $\mathrm{J}_{0}(\cdot)$ are respectively the wave number and the Bessel function of the first kind of order zero.

Nevertheless, it is recommended to confirm the results of microstrip antenna designs through the approximate expressions given in (1) to (8), by comparison to full-wave analyses' results based on electromagnetic theory. In fact, full-wave methods are implemented in commercial softwares like Ansoft Designer and Ansoft HFSS [13], [14], to perform accurate microwave circuits simulation and design, including antennas and FSS structures.

Thereafter, $2.45 \mathrm{GHz}$ ink-based typical rectangular microstrip antennas are simulated, designed and fabricated on FR-4 fiberglass and glass substrates, for performances evaluation. Simulation and design are carried out using Ansoft Designer software, that employs a full-wave formulation based on the method of moments (MoM), to ensure accurate analyses. All the antennas are fed using a $50 \Omega$ microstrip line.

The fabrication of the ink-based rectangular microstrip antennas prototypes is performed using simple spray with micro paint equipment on a dielectric layer mounted on a ground plane, while a conventional technique for microwave integrated circuits (MIC) is used to fabricate the antenna on copper clad laminate.

Fig. 6 shows photographs of three patch antenna prototypes on fiberglass substrate, namely FR-4, with relative permittivity, $\varepsilon_{r}, 4.4$, loss tangent, $\tan \delta, 0.02$, and height, $h, 1.57 \mathrm{~mm}$. The first prototype, shown in Fig. 6(a), is fabricated using a typical copper clad laminate, the second one, shown in Fig. 

DOI: http://dx.doi.org/10.1590/2179-10742019v18i21554

6(b), is painted with carbon ink of the CHIPsce brand, commonly used in electronics circuits for conductive traces' repairs, and the third one, shown in Fig. 6(c), is painted with the fabricated silver ink, which is synthesized from nitrocellulose.

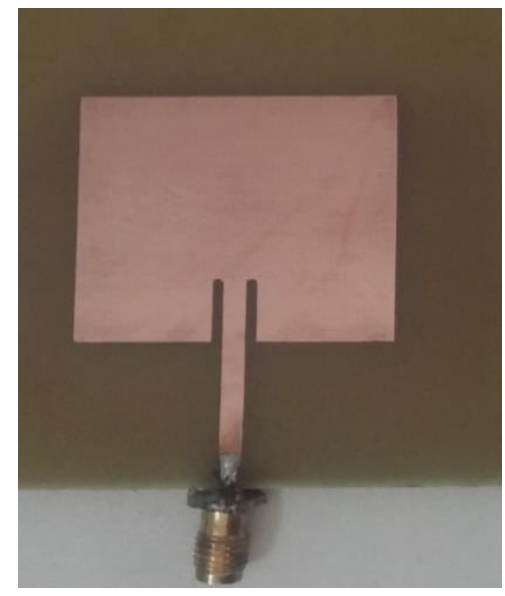

(a)

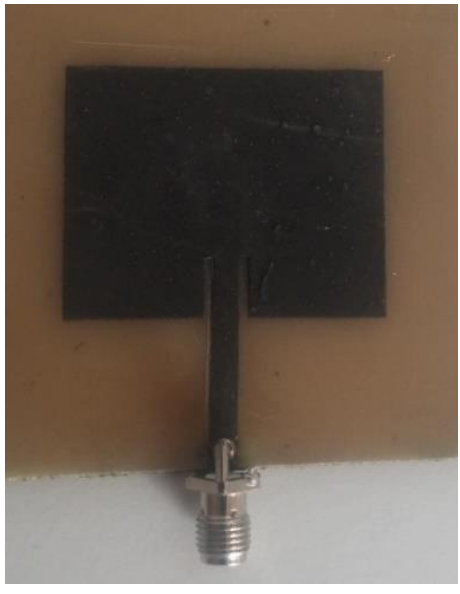

(b)

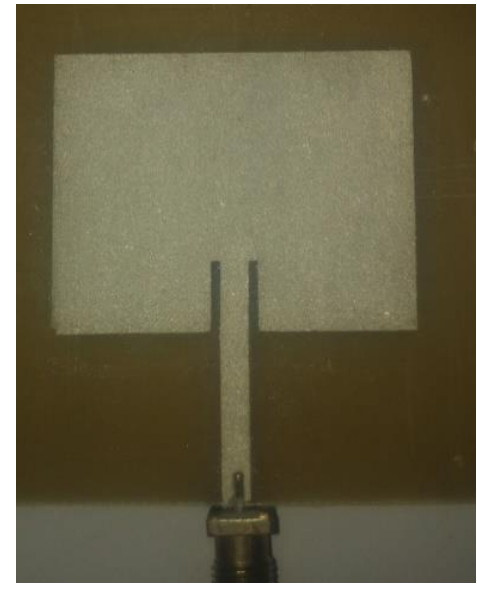

(c)

Fig. 6. Photographs of the microstrip patch antenna prototypes on fiberglass (FR-4) substrate (a) using a typical copper clad laminate, (b) painted with commercial carbon ink and (c) painted with the fabricated silver ink.

The main structural parameters (Fig. 5) of the patch antenna prototypes on fiberglass substrate shown in Fig. 6, are given in Table II. These dimensions values were defined using (1) to (5) and then adjusted with Ansoft HFSS, for Wi-Fi operation at $2.45 \mathrm{GHz}$. A very thin conducting patch made out of copper is considered. For comparison purpose, the conducting patches and feeding microstrip lines of the antenna prototypes shown in Fig. 6 were fabricated with the same dimensions, being composed of a metallic thin plate, Fig. 6(a), painted with carbon ink, Fig. 6(b), and painted with silver ink Fig. 6(c).

Table II. Dimensions of the Fabricated Patch Antennas on Fiberglass Substrate.

\begin{tabular}{cc}
\hline Parameters & Values \\
\hline \hline $\mathrm{W}$ & $37.26 \mathrm{~mm}$ \\
$\mathrm{~L}$ & $28.84 \mathrm{~mm}$ \\
$\mathrm{~W}_{0}$ & $3.0 \mathrm{~mm}$ \\
$\mathrm{~L}_{0}$ & $17.7 \mathrm{~mm}$ \\
$\mathrm{x}_{0}$ & $1.0 \mathrm{~mm}$ \\
$\mathrm{y}_{0}$ & $6.9 \mathrm{~mm}$ \\
$\mathrm{~h}$ & $1.57 \mathrm{~mm}$ \\
\hline
\end{tabular}

The patch antenna prototypes (Fig. 6) were measured for the operating range from $1.0 \mathrm{GHz}$ to 4.5 GHz. Measurements were performed using an R\&S ZVB14 vector network analyzer.

The measured results for the reflection coefficient of the antenna prototypes (Fig. 6) are shown in Fig. 7, along with simulated results using Ansoft Designer software, for comparison purpose. 


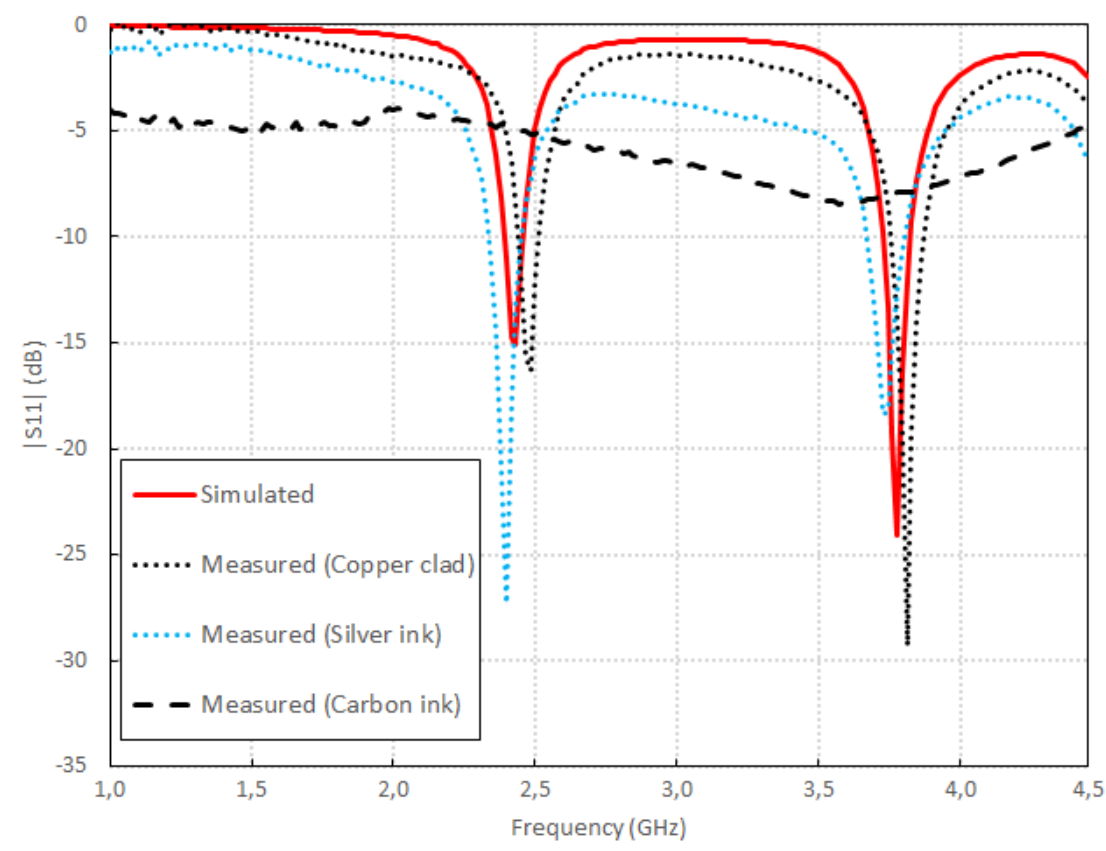

Fig. 7. Simulation and measurement results for the reflection coefficient of the antenna prototypes on the fiberglass (FR4) substrate using a copper clad laminate, Fig. 6(a), painted with carbon ink, Fig. 6(b), and painted with the fabricated silver ink Fig. 6(c).

The impedance measurement results are presented in Fig. 8 for the antenna prototypes shown in Fig. 6(a), where the patch is made out of copper, and Fig. 6(c), where the patch is painted with silver ink.

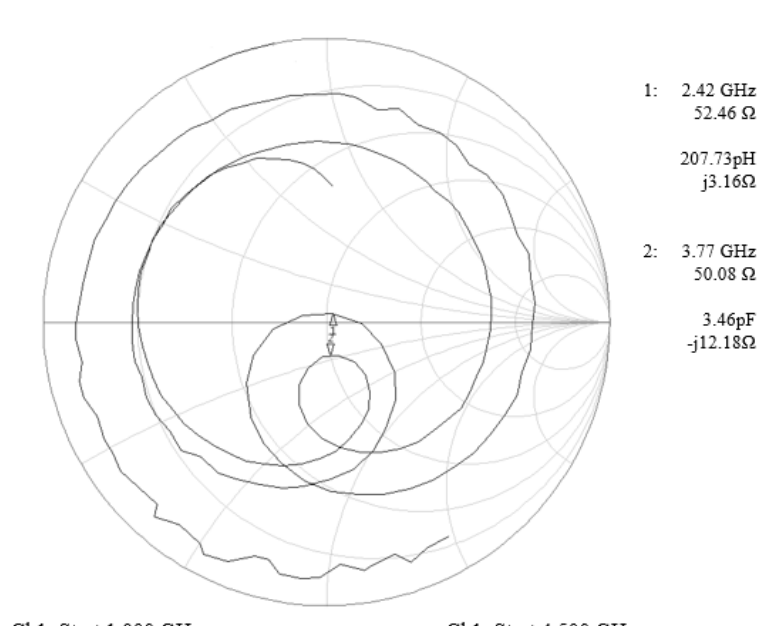

Ch1: Start $1.000 \mathrm{GHz}$

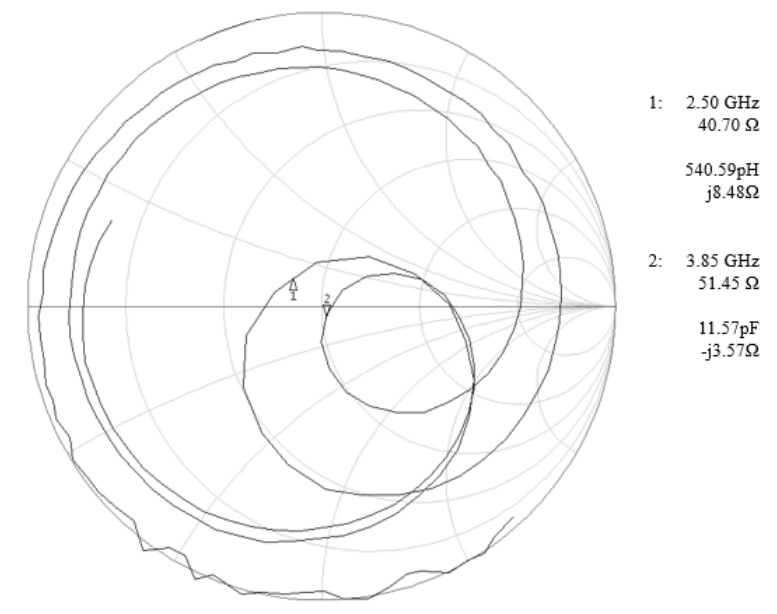

Ch1: Start $1.000 \mathrm{GHz}$

(b)

Fig. 8. Impedance measured results for the antenna prototypes (a) painted with silver ink and (b) on a typical copper clad laminate.

The simulated and measured results for the antenna prototypes with silver ink painted and copper patch elements are summarized and compared in Table III. 
TABle III. Simulation AND MEASUREMENT RESUltS FOR THE CONSIDERED PATCH ANTENNAS ON THE FIBERGLASS SUBSTRATE

\begin{tabular}{c|c|c|c|c}
\hline \multirow{2}{*}{ Parameters } & \multicolumn{2}{|c|}{ Silver patch element } & \multicolumn{2}{c}{ Copper patch element $^{2}$} \\
\hline & Simulated $^{1}$ & Measured $^{2}$ & Simulated $^{1}$ & Measured $^{1}$ \\
\hline $1^{\text {rst }}$ resonance & & & & \\
$\mathrm{f}_{\mathrm{r}}(\mathrm{GHz})$ & 2.43 & 2.42 & 2.45 & 2.50 \\
$\mathrm{~S} 11(\mathrm{~dB})$ & -16.46 & -27.28 & -15.08 & -16.29 \\
$\mathrm{BW}(\mathrm{MHz})$ & 90 & 110 & 90 & 70 \\
$\mathrm{BW}(\%)$ & 3.70 & 4.64 & 3.67 & 2.8 \\
$\mathrm{R}+\mathrm{jX}(\Omega)$ & $36.95-\mathrm{j} 0.77$ & $52.46+\mathrm{j} 3.16$ & $34.71+\mathrm{j} 2.89$ & $40.70+\mathrm{j} 8.48$ \\
\hline $2^{\text {nd }}$ resonance & & & & 3.85 \\
$\mathrm{f}_{\mathrm{r}}(\mathrm{GHz})$ & 3.82 & 3.77 & 3.82 & -29.31 \\
$\mathrm{~S} 11(\mathrm{~dB})$ & -21.54 & -18.35 & -24.09 & 105 \\
$\mathrm{BW}(\mathrm{MHz})$ & 90 & 120 & 90 & 2.72 \\
$\mathrm{BW}(\%)$ & 2.36 & 3.18 & 2.36 & $51.45-\mathrm{j} 3.57$ \\
$\mathrm{R}+\mathrm{jX}(\Omega)$ & $45.47-\mathrm{j} 6.62$ & $50.08-\mathrm{j} 12.18$ & $46.28-\mathrm{j} 4.73$ & \\
\hline
\end{tabular}

${ }^{1}$ Metallic very thin plate.

${ }^{2}$ Metallic ink-based.

The simulated and measured results for the patch antennas on fiberglass substrate using copper clad laminate and painted with silver ink are in good agreement, as shown in Table III. The observed agreement confirms that the manufactured silver ink exhibits a good potential to be used in the fabrication of painted microstrip patch antennas on a fiberglass substrate, which is a simple and efficient alternative to conventional techniques.

Thereafter, the manufactured silver ink was used in the fabrication of a microstrip patch antenna on a glass substrate, to explore the simplicity and flexibility provided by this manufacturing technique.

Fig. 9 shows a photograph of the rectangular microstrip patch antenna prototype fabricated on a glass substrate with relative permittivity $\varepsilon_{r}=5.5$ and height $h=1.4 \mathrm{~mm}$. The structural parameters (Fig. 5) are given in Table IV. The patch element was painted by simple air spraying using a pressurized reservoir which is the same technique previously used.

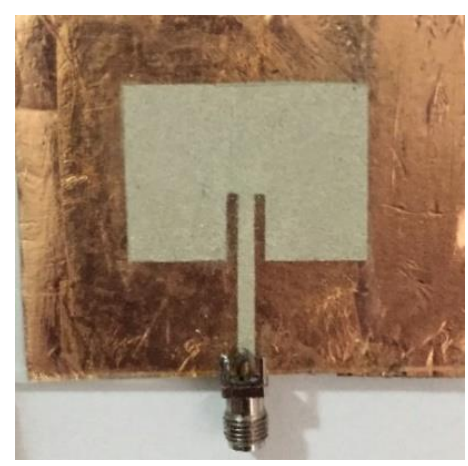

Fig. 9. Photograph of the microstrip patch antenna prototype on the glass substrate painted with the fabricated silver ink. 
TABLE IV. DiMENSIONS OF THE FABRICATED PATCH ANTENNA ON THE GLASS SUBSTRATE.

\begin{tabular}{cc}
\hline Parameters & Values \\
\hline \hline $\mathrm{W}$ & $34.00 \mathrm{~mm}$ \\
$\mathrm{~L}$ & $25.9 \mathrm{~mm}$ \\
$\mathrm{~W}_{0}$ & $2.26 \mathrm{~mm}$ \\
$\mathrm{~L}_{0}$ & $15.26 \mathrm{~mm}$ \\
$\mathrm{x}_{0}$ & $1.4 \mathrm{~mm}$ \\
$\mathrm{y}_{0}$ & $9.0 \mathrm{~mm}$ \\
$\mathrm{~h}$ & $1.4 \mathrm{~mm}$ \\
\hline
\end{tabular}

The microstrip patch antenna shown in Fig. 9 was measured for the operating range from $1.0 \mathrm{GHz}$ to 4.5 GHz. Measurements were performed using an R\&S ZVB14 vector network analyzer.

The measured results for the reflection coefficient of the antenna prototype shown in Fig. 9, along with simulated results using Ansoft Designer software, are shown in Fig. 10, for comparison purpose. The impedance measurement results are shown in Fig. 11.

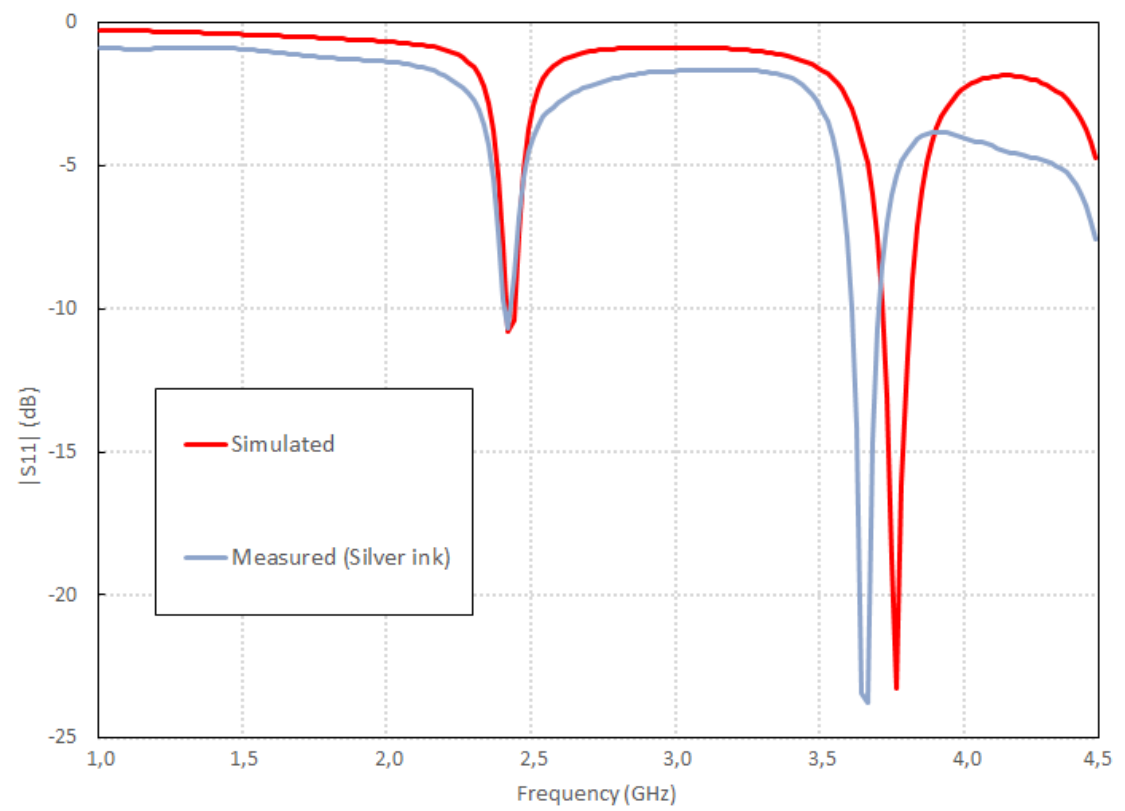

Fig. 10. The simulated and measured results for the reflection coefficient frequency response for the antenna on the glass substrate painted with silver ink (Fig. 9). 


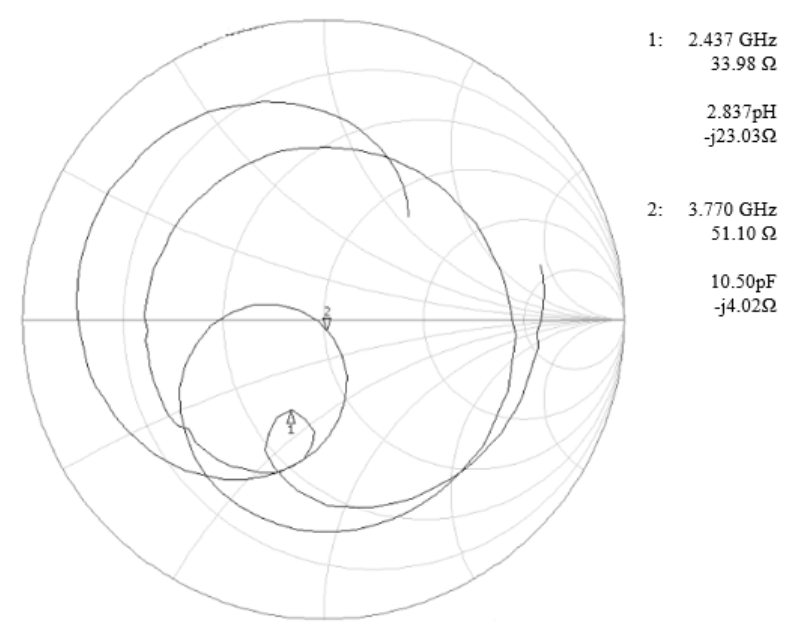

Ch1: Start $2.000 \mathrm{GHz}$

Ch1: Start $4.500 \mathrm{GHz}$

Fig. 11. Impedance measured results for the antenna prototype on the glass substrate painted with silver ink.

The simulated and measured results for the antenna prototype on glass substrate with patch elements painted with silver ink are summarized and compared in Table $\mathrm{V}$ showing a very good agreement in all cases.

\section{TABle V. Simulation AND Measurement Results For the Considered PatCH Antenna On Glass} SUBSTRATE

\begin{tabular}{|c|c|c|}
\hline \multirow[t]{2}{*}{ Parameters } & \multicolumn{2}{|c|}{ Silver patch element } \\
\hline & Simulated $^{1}$ & Measured $^{2}$ \\
\hline \multicolumn{3}{|l|}{$1^{r s t}$ resonance } \\
\hline $\mathrm{f}_{\mathrm{r}}(\mathrm{GHz})$ & 2.44 & 2.44 \\
\hline $\mathrm{S} 11(\mathrm{~dB})$ & -10.8 & -10.6 \\
\hline $\mathrm{BW}(\mathrm{MHz})$ & 20 & 22 \\
\hline BW (\%) & 0.8 & 0.9 \\
\hline $\mathrm{R}+\mathrm{jX}(\Omega)$ & $30.4-\mathrm{j} 12.9$ & $33.98-\mathrm{j} 23.0 .3$ \\
\hline \multicolumn{3}{|l|}{$2^{\text {nd }}$ resonance } \\
\hline $\mathrm{f}_{\mathrm{r}}(\mathrm{GHz})$ & 3.80 & 3.77 \\
\hline $\mathrm{S} 11(\mathrm{~dB})$ & -23.3 & -23.8 \\
\hline $\mathrm{BW}(\mathrm{MHz})$ & 88 & 87 \\
\hline $\mathrm{BW}(\%)$ & 2.3 & 2.3 \\
\hline $\mathrm{R}+\mathrm{j} \mathrm{X}(\Omega)$ & $45-\mathrm{j} 4.05$ & $51.10-\mathrm{j} 4.02$ \\
\hline
\end{tabular}

${ }^{1}$ Metallic thin plate.

${ }^{2}$ Metallic ink-based.

As expected, similar results were obtained for the parameters of the silver ink painted microstrip patch antenna on a fiberglass substrate (Table III) and on a glass substrate (Table V). This happens because the design values of the dimensions of these antennas (substrate height and patches' widths and 
lengths) and the relative permittivity values of glass and fiberglass substrates are close.

\section{Bioinspired Frequency Selective Surfaces Design, Fabrication and Results}

Frequency selective surfaces (FSSs) are spatial electromagnetic filters which typically are composed of bidimensional periodic arrays on dielectric substrates. Therefore, depending on the element type (aperture or conductive patch) used in the unit cell; the FSS will behave like a bandpass filter (aperture elements) or a band-reject filter (conductive patch elements). The FSS filtering properties depends on the chosen substrate material, cell size, patch or aperture dimensions and format, and array periodicity [15], [16].

Typical FSS patch elements are shown in Fig. 12 and can be printed on one or multiple dielectric layers, depending on the desired frequency performance. Similarly, thin metal sheets with aperture elements with the shapes shown in Fig. 12 can be used in the development of frequency selective surfaces (FSS).

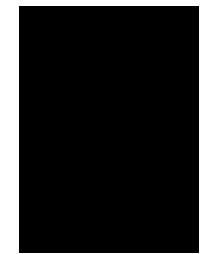

(a)

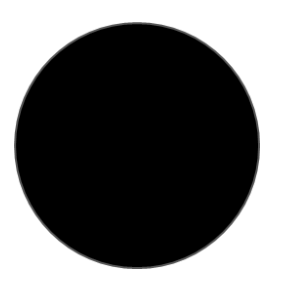

(b)

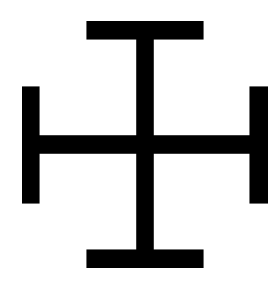

(c)

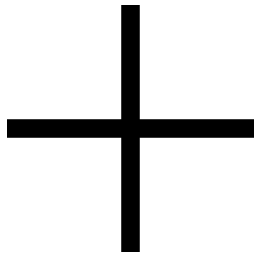

(d)

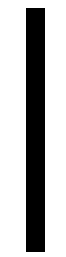

(e)

Fig. 12. Typical array elements of FSS structures are: (a) rectangular patch, (b) circular patch, (c) Jerusalem cross, (d) cross dipole, and (d) thin dipole.

Recently, new geometries have been used as elements of FSS arrays, including slotted patches [17], fractals [18], combination of similar and dissimilar parallel coupled [19] and broadside-coupled elements [20], [21], split ring patches [22], and paper-based substrate [23].

The geometry of a bioinspired-shaped patch element is proposed for the development of an innovative FSS structure. The proposed geometry is inspired on the leaf of the Oxalis triangularis plant, showing that bio-inspired patch elements are suitable for FSS designs.

In addition, the choice of the shape of leaves to define new FSS patch element geometries is related to the fact that in nature their shapes were optimized over years to better absorb light energy from the sun. In addition, some of them present self-similar structures, looking like fractal geometries.

In this work, two $3.5 \mathrm{GHz}$ ink-based bioinspired frequency selective surfaces (FSSs) are simulated, designed and fabricated on FR-4 fiberglass substrate. The first one is fabricated using a typical copper clad laminate and the second one is painted with the manufactured silver ink.

Simulation and design are carried out using Ansoft Designer software that implements a full-wave electromagnetic formulation based on the method of moments (MoM), to ensure accurate analyses. The 

DOI: http://dx.doi.org/10.1590/2179-10742019v18i21554

chosen shape of the FSS array element is based on the Oxalis triangularis plant's leaf which has three symmetry axes with leaves that looks like triangles, as shown in Fig. 13(a). The bioinspired FSS cell is designed using the Ansoft Designer software with the unit cell illustrated in Fig. 13(b).

The fabrication of the ink-based FSS prototype is performed using simple spray with micro paint equipment on a dielectric layer, while a conventional technique for microwave integrated circuits (MIC) is used to fabricate the FSS on copper clad laminate.

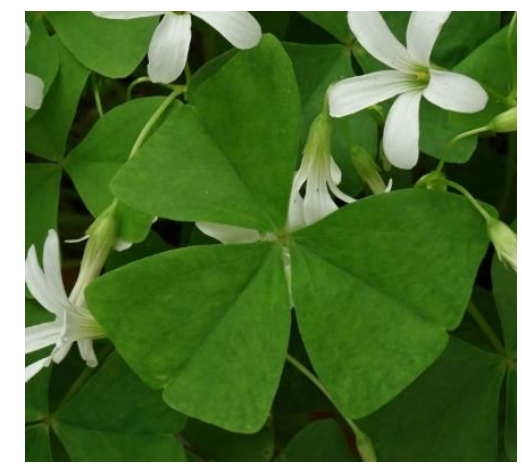

(a)

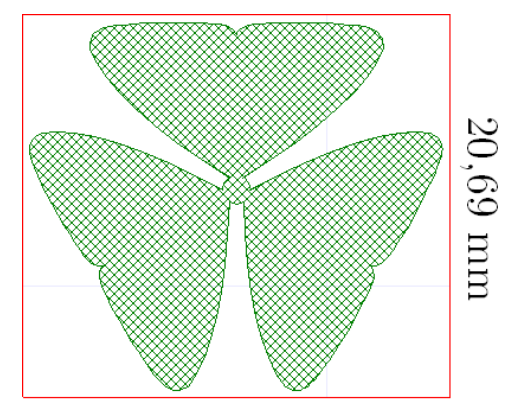

$23,11 \mathrm{~mm}$

(b)

Fig. 13. The Oxalis triangularis plant's leaf shape. (a) Photograph and (b) unit cell.

Fig. 14 shows photographs of two FSSs prototypes on FR-4 fiberglass substrate with relative permittivity, $\varepsilon_{r}=4.4$, loss tangent, $\tan \delta=0.02$, and height, $h=1.57 \mathrm{~mm}$. The first prototype, shown in Fig. 14(a), is fabricated using a typical copper clad laminate and the second one, shown in Fig. 14(b), is painted with the fabricated silver ink, which is synthesized from nitrocellulose.

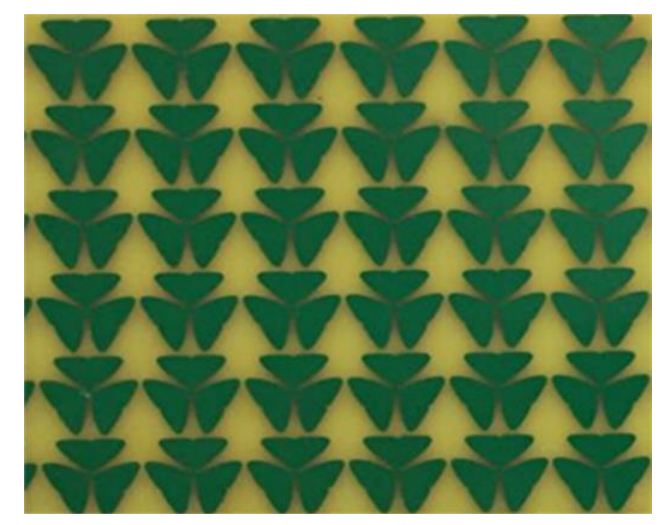

(a)

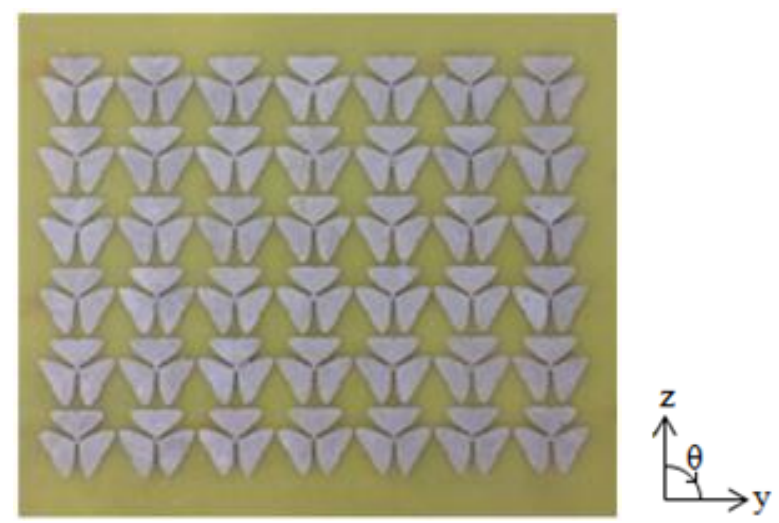

(b)

Fig. 14. Photographs of FSS prototypes with Triangularis leaf patch elements: (a) using copper clad laminate and (b) painted with silver ink.

To evaluate the effectiveness of using the manufactured silver ink, a comparison is performed between the simulated and measured results of the transmission coefficient of the FSS prototypes shown in Fig. 14.

For measurement purpose, the FSS is placed between two horn antennas connected to a network 
analyzer, for microwave transmission (Tx) and reception (Rx), so that the FSS frequency response is verified through the transmission coefficient $\left(\mathrm{S}_{21}\right)$ between them, as shown in Fig. 15.

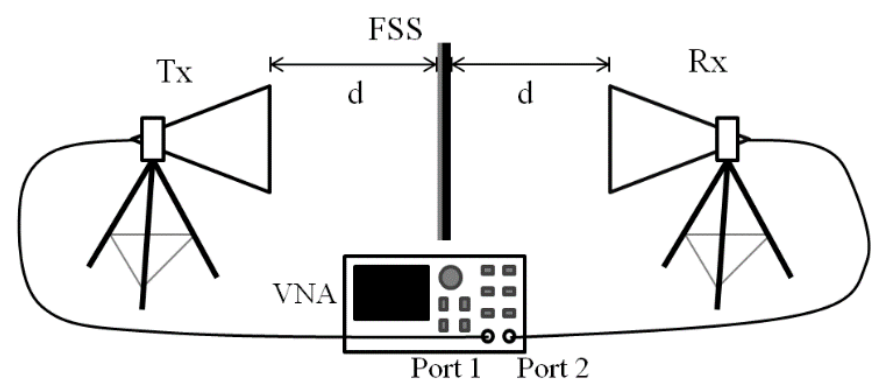

Fig. 15. Illustration of the measurement setup for experimental characterization of the bioinspired FSS.

The simulated and measured results for the FSSs transmission coefficient $S_{21}(\mathrm{~dB})$ frequency responses are shown in Fig. 16, for normal incident waves. Measurements were performed for the FSS placed at $\theta=0^{\circ}$, for transverse electric (TE) polarization and at $\theta=90^{\circ}$, for transverse magnetic (TM) polarization, where $\theta$ is the rotation angle indicated in Fig. 14. The simulated and measured results are summarized in Table VI. A good agreement is observed between simulation and measurements results.

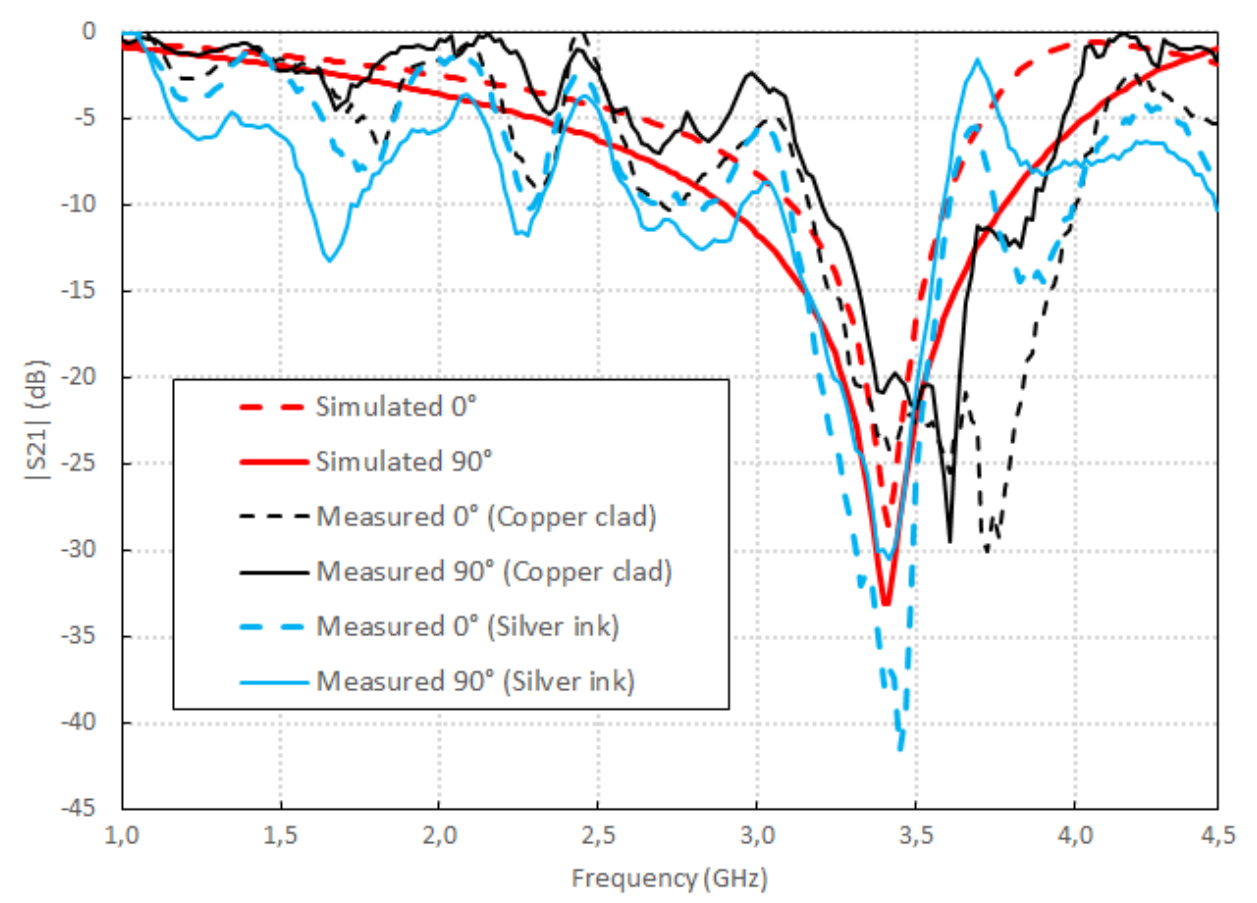

Fig. 16. Simulation and measurement results of the transmission coefficient, S21 (dB), for the ink-based FSSs on fiberglass substrate (a) using a copper clad laminate, Fig. 14(a), and painted with silver ink, Fig. 14(b). Rotation angles are $\theta=0^{\circ}$, for TE polarization, and $\theta=90^{\circ}$, for $\mathrm{TM}$ polarization. 
Table VI. Simulation and Measurement for the FSS Manufactured with CopPer Clad and Silver InK.

\begin{tabular}{cccc}
\hline Parameters & Simulated & Copper clad & Silver ink \\
\hline \multicolumn{2}{c}{ TE Polarization $\left(\theta=0^{\circ}\right)$} & & \\
fr $(\mathrm{GHz})$ & 3.45 & 3.64 & 3.45 \\
S21 $(\mathrm{dB})$ & -28.54 & -29.5 & -30.51 \\
BW $(\mathrm{MHz})$ & 500 & 660 & 500 \\
BW $(\%)$ & 14.49 & 18.13 & 14.49 \\
\hline TM Polarization $\left(\theta=90^{\circ}\right)$ & & \\
fr $(\mathrm{GHz})$ & 3.43 & 3.45 & 3.48 \\
S21 $(\mathrm{dB})$ & -33.10 & -24.18 & -41.6 \\
BW $(\mathrm{MHz})$ & 860 & 840 & 510 \\
BW $(\%)$ & 25.07 & 24.35 & 14.66 \\
\hline
\end{tabular}

${ }^{1}$ Metallic thin plate

${ }^{2}$ Metallic ink-based

\section{RESULTS AND DISCUSSION}

The frequency response results are presented in Fig. 7, for the patch antennas on fiberglass substrate, and in Fig. 9, for the patch antenna on the glass substrate, enabling a comparison between the simulated and measured results for the resonant frequency, reflection coefficient and input impedance, for example.

For the copper clad patch antenna on fiberglass substrate, shown in Fig. 6(a), the measured results indicate resonant frequencies at $2.50 \mathrm{GHz}$ (with a deviation of $2.04 \%$ relative to the simulated value of $2.45 \mathrm{GHz}$ ) and $3.85 \mathrm{GHz}$ (with a deviation of $0.78 \%$ relative to the simulated value of $3.82 \mathrm{GHz}$ ).

For the silver ink patch antenna on fiberglass substrate, shown in Fig. 6(c), the measured results indicate resonant frequencies at $2.42 \mathrm{GHz}$ (with a deviation of $0.41 \%$ relative to the simulated value of $2.43 \mathrm{GHz}$ ) and $3.77 \mathrm{GHz}$ (with a deviation of $1.31 \%$ relative to the simulated value of $3.82 \mathrm{GHz}$ ).

In the investigation, the structural parameters of the antennas' prototypes are the same, except for the fabrication processes, one painting with silver ink and the other one using chemistry to remove the copper plating (or by corrosion with iron chloride/perchlorate) of the copper clad laminate.

The obtained measured results for the resonant frequencies of the patch antenna painted with silver ink and the patch antenna using the commercial copper clad laminate, are compared and deviations of $3.2 \%$ (at the first resonance band) and 2.08\% (at the second band) are obtained. Therefore, a good agreement is observed despite the differences between the physical nature of the compared patch antennas, one manufactured using a copper thin plate and the other one a metallic silver ink film.

For the silver ink painted patch antenna on glass substrate, shown in Fig. 9, the measured results indicate resonant frequencies at $2.44 \mathrm{GHz}$ (without deviation relative to the simulated value of 2.44 $\mathrm{GHz}$ ) and $3.77 \mathrm{GHz}$ (with a deviation of $0,79 \%$ relative to the simulated value of $3.80 \mathrm{GHz}$ ). In addition, a very good agreement is observed between simulated and measured results for the antenna parameters as shown in Table VI. 
The observed agreement indicates that the manufactured silver ink proved to be suitable for the development of microstrip antennas on glass and fiberglass substrates with some intrinsic advantages related to the ease manufacturing process, application on various dielectric substrates (including planar and curved structures), and printing of conductive patches with complex shapes.

Fig. 16 presents the measured and simulated results for the prototypes of the bioinspired FSSs (with bioinspired Oxalis triangularis type elements) fabricated using copper clad laminate, shown in Fig. 14(a), and painted with silver ink, shown in Fig. 14(b).

For TE polarization, the FSS simulated results indicate a resonant frequency at $3.45 \mathrm{GHz}$ while the measured results for the FSS fabricated using a copper clad laminate the resonance occurs at $3.64 \mathrm{GHz}$ (with a deviation of $5.51 \%$ relative to the simulated value). For the FSS with patch elements painted with silver ink, resonance happens at $3.45 \mathrm{GHz}$ (without deviation relative to the simulated value), indicating agreement with the obtained results for the FSS fabricated using copper clad laminate.

For TM polarization, the simulated result indicates a resonant frequency at $3.43 \mathrm{GHz}$ while the measured results for the FSS fabricated using a copper clad laminate the resonance occurs at $3.45 \mathrm{GHz}$ (with a deviation of $0.58 \%$ relative to the simulated value). For the FSS with patch elements painted with silver ink, resonance happens at $3.48 \mathrm{GHz}$ (with a deviation of $1.46 \%$ relative to the simulated value), indicating good agreement with the obtained results for the FSS fabricated using copper clad laminate.

In addition, Fig. 16 and Table VI show that the manufactured bioinspired FSSs exhibit good angular stability, proving to be suitable for wireless communication systems.

\section{CONCLUSION}

Two conductive inks, one sold commercially, based on carbon, which did not prove to be appropriate to the microstrip antennas manufacture, and the other one based on nitrocellulose and metallic silver powder, manufactured in this work, were used in the fabrication of microstrip antennas on fiberglass and glass substrates. It has been observed that the simulated and measured results obtained for the prototype antenna painted with silver ink are in good agreement, even when compared to the prototype fabricated using copper clad laminate results. The antennas' prototypes painted with silver ink (on glass and fiberglass substrates) were tested to determine their performances related to the measurement of the input reflection coefficient $\left(s_{11}\right)$, dealing mainly with the impedance matching results. To prove the versatility of the manufactured silver ink, a bioinspired FSS was fabricated to investigate the silver ink and fabrication technique performances in the development of a larger and complex printed circuit geometry. Once again, it has been observed that the simulated and measured results obtained for the FSS painted with silver ink are in good agreement. The FSS prototype painted with silver ink (on glass substrates) was tested to determine its performance related to the measurement of the transmission coefficient $\left(\mathrm{s}_{21}\right)$, dealing directly with the wave filtering results. Therefore, the proposed prototypes painted with the manufactured silver ink were tested for both equivalent circuit and wave scattering 
parameters, showing consistent performances when compared to prototypes fabricated with thin metallic plates using copper clad laminates and the conventional technique based on perchloride of iron corrosion. Simulations and analyses were performed using Ansoft Designer and HFSS softwares. Another important issue is that nitrocellulose can be combined with other resins to give, among other qualities, greater flexibility and adhesion to the films, demonstrating potential for use on flexible substrates in conductive film formation.

\section{ACKNOWLEDGMENTS}

This work was partially supported by CNPq, under covenant 573939/2008-0 (INCT-CSF), Federal University of Rio Grande do Norte (UFRN), Federal Institute of Education, Science and Technology of Rio Grande do Norte (IFRN) and Federal Institute of Education, Science and Technology of Paraíba (IFPB).

\section{REFERENCES}

[1] C. A. Balanis, Antenna Theory - Analysis and Design, New York: John Wiley \& Sons, 2005.

[2] D. Unnikrishnan, D. Kaddour, S. Tedjini, E. Bihar, and M. Saadaoui, "CPW-fed inkjet printed UWB antenna on ABS-PC for integration in molded interconnect devices technology," IEEE Antennas Wirel. Propag. Lett., vol. 14, pp. 1125-1128, 2015.

[3] W. Su, B. Cook, M. Tentzeris, C. Mariotti, and L. Roselli, “A novel inkjet-printed microfluidic tunable coplanar patch antenna," Proc. IEEE Antennas Propag. Soc. Int. Symp. (APSURSI), Memphis, TN, USA, pp. 858-859, 2014

[4] W. G. Whittow, A. Chauraya, J. C. Vardaxoglou, Y. Li, R. Torah, K. Yang, S. Beeby, and J. Tudor, "Inkjet-printed microstrip patch antennas realized on textile for wearable applications," IEEE Antennas Wirel. Propag. Lett, vol. 13, pp. 71-74, 2014.

[5] J. Bito, B. Tehrani, B. Cook, and M. Tentzeris, "Fully inkjet-printed multilayer microstrip patch antenna for Ku-band applications," Proc. IEEE Antennas Propag. Soc. Int. Symp. (APSURSI), Memphis, TN, USA, pp. 854-855, 2014.

[6] S. V. Stovbun, S. N. Nikol'skii, P. V. Mel'nikov, M. G. Mikhaleva, A. N. Shchegolikhin, D. V. Zlenko, V. A. Tverdislov, D. S. Gerasimov, and A. D. Rogozin, "Chemical physics of cellulose nitration,” Russ. J. Phys. Chem. B, vol. 10, no. 2, pp. 245-259, 2016.

[7] L. C. Duarte, P. L. Juchem, G. M. Pulz, T. M. M. Brum, N. Chodur, A. Liccardo, A. C. Fischer, and R. B. Acauan, “Aplicações de microscopia eletrônica de varredura (MEV) e sistema de energia dispersiva (EDS) no Estudo de Gemas: Exemplos Brasileiros (in Portuguese)," Pesquisas em Geociências, vol. 30, no. 2, pp. 3-15, 2003.

[8] V. Junqueira, Percolação e Caracterização Elétrica em Tintas Condutoras, Ph.D. Dissertation (in Portuguese), Federal University of Itajubá, MG, Brazil, 2012.

[9] S. R. Broadbent and J. M. Hammersley, "Percolation processes. I. Crystal and mazes", Math. Proc. Camb. Philos. Soc., vol. 53, no. 3, pp. 629-641, 1957.

[10] A. G. Hunt and R. Ewing, Percolation Theory for Flow in Porous Media (Lect. Notes Phys., 771), Germany: Springer, 2009.

[11] G. Kumar and K. P. Ray, Broadband Microstrip Antennas, USA: Artech House, 2003.

[12] M. A. Matin and A. I. Sayeed, “A design rule for inset-fed rectangular microstrip patch antenna," WSEAS Trans. Commun., vol. 9, no. $1,2010$.

[13] R. C. Filho, J. H. Araújo, M. F. Ginani, A. G. D'Assunção Junior, R. A. Martins, A. G. D'Assunção, and L. M. Mendonça, "Simulation and measurement of inset-fed microstrip patch antennas on BiNbO4 substrates”, Microw. Opt. Technol. Lett., vol. 52, pp. 1034-1036, 2010.

[14] E. E. C. Oliveira, M. S. Vieira, P. H. F. Silva, M. A. Oliveira, and A. G. D'Assunção, "Dielectric resonator antenna based in ZrTiO with high dielectric constant," J. Microw. Optoelectron. Electromagn. Appl., vol. 14, no. 2, 2015.

[15] B. A. Munk, Frequency Selective Surfaces: Theory and Design, Wiley, New York, 2000.

[16] T. K. Wu, Frequency-Selective Surface and Grid Array, New York: John Wiley \& Sons, 1995.

[17] P. B. C. Medeiros, V. P. Silva Neto, and A. G. D'Assunção, “A compact and stable design of FSS with radial slit circular elements using an iterative method," Microw. Opt. Technol. Lett., vol. 57, pp. 729-733, 2015. 
DOI: http://dx.doi.org/10.1590/2179-10742019v18i21554

[18] M. R. Silva, P. H. F. Silva, C. L. Nóbrega, and A. G. D'Assunção, "Optimal design of frequency selective surfaces with fractal motifs," IET Microw. Antennas Propag., vol. 8, pp. 627-631, 2014.

[19] V. P. Silva Neto, A. G. D'Assuncao, and H. Baudrand, "Analysis of finite size nonuniform stable and multiband FSS using a generalization of the WCIP method," IEEE Trans. Electromag. Compat., vol. 60, no. 6, pp. 1802-1810, 2018.

[20] D. B. Brito, A. G. D’Assunção, R. H. C. Maniçoba, and X. Begaud, "Metamaterial inspired Fabry-Pérot antenna with cascaded frequency selective surfaces," Microw. Opt. Technol. Lett., vol. 55, pp. 981-985, 2013.

[21] I. S. Syed, Y. Ranga, L. Matekovits, K. P. Esselle, and S. G. Hay, "A single-layer frequency-selective surface for ultrawideband electromagnetic shielding," IEEE Trans. Electromagn. Compat., vol. 56, no. 6, pp. 1404-1411, 2014.

[22] S. N. Zabri, R. Cahill, and A. Schuchinsky, "Polarisation independent split ring frequency selective surface," Electron. Lett., vol. 49, no. 4, pp. 245-246, 2013.

[23] R. Sivasamy, L. Murugasamy, M. Kanagasabai, E. F. Sundarsingh, and M. Gulam Nabi Alsath, "A low-profile paper substrate-based dual-band FSS for GSM shielding," IEEE Trans. Electromagn. Compat., vol. 58, no. 2, pp. 611-614, 2016. 